\title{
Avaliação dos focos de calor e da fórmula de Monte Alegre no parque Nacional da Chapada dos Guimarães
}

\author{
Arlindo de Paula Machado Neto ${ }^{1 *}$, Antonio Carlos Batista ${ }^{2}$, Ronaldo Viana Soares², Daniela Biondi², Riubi Lopes de Morais ${ }^{1}$ \\ ${ }^{1}$ Universidade Federal de Mato Grosso, Av. Fernando Corrêa da Costa, 2367, Boa Esperança, CEP 78060-900, Cuiabá, MT, Brasil \\ ${ }^{2}$ Universidade Federal do Paraná, Av. Pref. Lothário Meissner, 632, Jardim Botânico, CEP 80210-170, Curitiba, PR, Brasil
}

\section{"Autor correspondente: \\ arlindo.neto08@gmail.com}

Termos para indexação:

Incêndios florestais

Unidade de conservação

Satélites

Index terms:

Forest fires

Conservation units

Satellites

Histórico do artigo:

Recebido em 02/05/2017

Aprovado em 27/09/2017

Publicado em 29/12/2017

doi: 10.4336/2016.pfb.37.92.1440
Resumo - O presente estudo teve por objetivo analisar o comportamento da Fórmula de Monte Alegre (FMA) e quantificar os focos de calor detectados por satélites de referência, comparando os mesmos com os incêndios ocorridos no Parque Nacional da Chapada dos Guimarães de 2007 a 2015. O monitoramento dos focos de calor foi realizado através de imagens dos satélites AQUA, TERRA e NOAA, cujos dados diários de focos detectados foram usados para compor a série temporal ao longo dos anos, permitindo a análise de tendências dos números de focos para o parque. Os dados foram adquiridos na plataforma do Instituto Nacional de Pesquisas Espaciais, na base de dados históricos do Instituto Nacional de Meteorologia e junto à gerência do parque. $\mathrm{Na}$ maioria dos anos houve uma superestimação do número de focos de calor em relação ao número de ocorrência dos incêndios. O satélite TERRA apresentou valores que mais se aproximaram do número de registros de fogo no parque. Observou-se que $87,69 \%$ dos incêndios foram validados em relação a FMA, onde $60 \%$ estavam na classe de perigo muito alto e $27,69 \%$ enquadraram-se na classe de perigo alto, demonstrando a efetividade da FMA em relação aos registros de incêndios ocorridos no parque.

\section{Evaluation of heat focuss and Monte Alegre formula in Chapada dos Guimarães National park}

\section{Introdução}

Milhares de hectares de florestas são queimadas em todo mundo a cada ano, gerando efeitos de grande impacto, tanto do ponto de vista econômico como ambiental. A Rede Sul Americana de Incêndios Florestais diz que somente nos últimos trinta anos estima-se que 
tenham ocorrido na América do Sul cerca de 290.000 incêndios florestais, afetando uma área equivalente a 51,7 milhões de ha (Global Fire Monitoring Center, 2007).

Existem diversas alternativas que podem ser adotadas para atenuar ou impedir a ocorrência de incêndios florestais em determinado local, porém a prevenção é a primeira linha de defesa contra os incêndios. Assim, mesmo adotando-se as melhores técnicas de prevenção, alguns incêndios fatalmente ocorrerão, necessitando de uma rápida e decidida ação de combate (Batista, 2009).

Durante a estação seca o fogo é um distúrbio frequente no Brasil. Grande parte das Unidades de Conservação (UC) vem sendo atingidas por incêndios florestais, todos os anos. Hoje, menos de 3\% da superfície do bioma Cerrado está protegida em UC's e mais de $60 \%$ da região já foi profundamente modificada pela ocupação antrópica, com lavouras diversas, pastagens e ocupação urbana (Cavalcanti, 2000).

Quando se trata da ação do fogo sobre as áreas naturais protegidas, destinadas à preservação dos recursos naturais, os efeitos do fogo devem ser criteriosamente avaliados para estabelecer programas de manejo que propiciem a melhor forma de recuperação dos ambientes modificados (Fiedler et al., 2006). De acordo com Soares \& Batista (2007), o monitoramento dos incêndios florestais por meio de imagens de satélites em nível nacional e em escalas regionais, é o meio mais eficiente e de baixo custo, quando comparado com os demais meios de detecção.

O Instituto Chico Mendes de Conservação da Biodiversidade (ICMBio), através da Coordenação Geral de Proteção Ambiental, possui metodologias para identificação e localização dos incêndios em UC's. Além disso, também são utilizados como um dos componentes dessa metodologia os dados de focos de calor detectados por satélites e disponibilizados pelo Instituto Nacional de Pesquisas Espaciais (Inpe). No entanto, existe certo grau de incerteza e imprecisão nos sistemas de detecção por satélites, sendo necessária, para seu refinamento, realizar validação em campo (ICMBio, 2010). De acordo com o INPE (2014), desde 1987 o sistema de aperfeiçoamento e detecção de queimadas vem sendo aprimorado com base na identificação dos focos de calor em imagens geradas e captadas a uma faixa termal média de $3,7 \mu \mathrm{m}$ a $4 \mu \mathrm{m}$ do espectro óptico, por meio de sensores a bordo de diversos satélites.
O INPE divulga dados derivados dos satélites de órbita polar AQUA, TERRA, NOAAs-15, 16, 17, 18 e 19, e dos satélites geoestacionários METEOSAT-02, GOES-12. Cada satélite polar produz dois imageamentos por dia, e os geoestacionários geram algumas imagens por hora, sendo que no total o INPE processa mais de 200 imagens por dia, especificamente para detectar focos de queima da vegetação. Com relação aos dados do sensor MODIS (AQUA e TERRA), o INPE desenvolveu um algoritmo próprio de detecção de focos de queima conservativo, de modo a minimizar os falsos alarmes associados a ruídos e ao reflexo solar ocasional em corpos d'água e solo exposto em imagens diurnas (Instituto Nacional de Pesquisas Espaciais, 2010).

O conhecimento do grau de perigo diário também se configura como uma ferramenta útil na programação das atividades de prevenção e combate aos incêndios florestais (Soares \& Batista, 2007).

A Fórmula de Monte Alegre (FMA), vem sendo utilizada por diversas empresas e instituições para estimar o grau de perigo de incêndio e subsidiar tais atividades. Sendo assim, o monitoramento do índice de perigo de incêndio florestal aliado ao monitoramento de variáveis meteorológicas possui importância na caracterização de regiões que apresentam potencialidades de ocorrência de incêndios (Deppe et al, 2004).

A utilização do índice é fundamental no planejamento das medidas de prevenção e para a adoção de ações rápidas e efetivas nas atividades de combate, visando reduzir perdas e, consequentemente, os prejuízos financeiros, sociais e ambientais advindos da ocorrência desses incêndios (Tetto et al., 2010b).

Assim, este trabalho teve por objetivo analisar os resultados da Fórmula de Monte Alegre comparando os mesmos com os dados de focos de calor e dos incêndios florestais ocorridos no Parque Nacional da Chapada dos Guimarães, no período de 2007 a 2015.

\section{Material e métodos}

O Parque Nacional da Chapada dos Guimarães (PNCG) está localizado no estado de Mato Grosso, nos municípios de Cuiabá e de Chapada dos Guimarães (Figura 1). Seu limite está a $26 \mathrm{~km}$ da área urbana de Cuiabá e a seis quilômetros de Chapada dos Guimarães, com uma área de 32.630 ha e entre as coordenadas geográficas $15^{\circ} 10^{\prime}$ e $15^{\circ} 30^{\prime} \mathrm{S}$ e $56^{\circ} 00^{\prime}$ e $56^{\circ} 40^{\prime} \mathrm{W}$. Por se encontrar dentro do Bioma Cerrado, apresenta uma grande diversidade biológica (Machado et.al. 2004). 


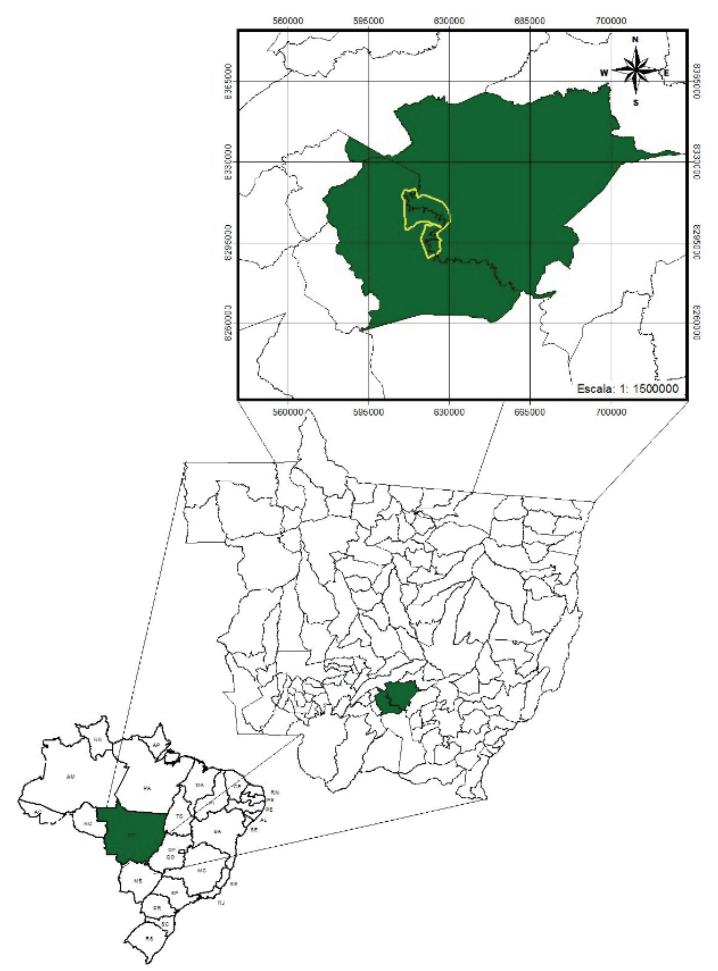

Figura 1. Localização da área de estudo

De acordo com a classificação de Köppen, o clima se enquadra nas categorias Aw e Cw (Ibama, 1995). Ambas caracterizam-se pela presença marcante de uma estação chuvosa (outubro a março) e uma seca (abril a setembro). Na estação seca ocorrem as "friagens", invasão da massa polar sobre o continente, levando a quedas bruscas de temperatura. As temperaturas médias anuais variam de $25^{\circ} \mathrm{C}$ (na Baixada Cuiabana) a $21,5^{\circ} \mathrm{C}$ (nos topos elevados da Chapada dos Guimarães), sendo que as temperaturas máximas diárias, na Baixada Cuiabana, podem superar os $38^{\circ} \mathrm{C}$ e as mínimas, no topo da Chapada, caem a menos de $5^{\circ} \mathrm{C}$ (Icmbio, 2009).

Segundo o Seplan (2007), o total pluviométrico anual encontra-se entre $1.650 \mathrm{~mm}$ e $2.100 \mathrm{~mm}$, sendo a umidade relativa de novembro a abril inferior a $80 \%$ e nos meses secos inferior a 60\% (Ibama, 1995).

Devido às variações de altitude $(250 \mathrm{~m}$ a $800 \mathrm{~m}) \mathrm{e}$ relevo (morros, chapadas e vales), o PNCG apresenta uma grande diversidade de ambientes, sendo que em cada um destes ambientes encontram-se várias formações vegetais específicas, principalmente savânicas e campestres (Couto et al., 2006).

Para realização do cruzamento de informações com a avaliação da Fórmula de Monte Alegre (FMA) e dos focos de calor em relação ao número de ocorrências dos incêndios florestais no PNCG, foi realizada a coleta e o processamento dos dados registrados durante o período de 2007 a 2015. Os dados referentes ao número de ocorrência dos incêndios foram coletados através dos registros de ocorrências de incêndios florestais (ROI's), fornecidos pela gerência do fogo (setor responsável pela catalogação dos incêndios) do PNCG.

Os registros continham informações como: número de ocorrências dos incêndios, extensão da área queimada, causas, locais de ocorrência e a época de ocorrência (distribuição pelos meses e dias da semana). Em relação ao número de focos de calor, foram utilizadas imagens a partir de dados dos satélites de referência: NOAA (que transporta o sensor AVHRR); AQUA e TERRA (ambos transportam o sensor MODIS). As imagens desses satélites foram escolhidas por serem mais indicados devido aos seus dados diários de focos detectados serem usados para compor a série temporal ao longo dos anos e assim permitir a análise de tendências nos números de focos para mesmas regiões e entre regiões em períodos de interesse, além de produzirem pelo menos dois conjuntos de imagens por dia em cada satélite. As imagens dos satélites geoestacionários não foram utilizadas pelos satélites ficarem na longitude de zero graus, não cobrindo a parte oeste do Brasil e da América do Sul, e pelo ângulo acentuado de visada dos mesmos que apresentam píxeis (elementos de resolução da imagem) distorcidos, com mais de $7 \mathrm{~km}$ de largura na região leste do Brasil. Todos os dados foram obtidos junto ao sistema de detecção do Instituto Nacional de Pesquisas Espaciais/Centro de Previsão de Tempo e Estudos Climáticos (INPE/CPTEC).

Após o processo de coleta das informações, analisouse os números de incêndios em relação à quantidade de focos de calor detectados, com o objetivo de comparar a quantidade de incêndios ocorridos em campo com as informações geradas por meio de imagens de satélites. $\mathrm{O}$ número de incêndios registrados no parque também foi comparado com a Fórmula de Monte Alegre, com o intuito de observar os resultados da fórmula nos dias em que houveram registros dos incêndios no parque.

A FMA foi calculada para o PNCG no período de 2007 a 2015. Este índice é cumulativo e utiliza como variáveis a umidade relativa do ar (de forma direta) e a precipitação pluviométrica, como fator restritivo ao cálculo (Tabela 1). 
Os dados meteorológicos diários de umidade relativa do ar e precipitação utilizados para o cálculo da FMA foram coletados no banco de dados históricos do Instituto Nacional de Meteorologia (INMET), da estação meteorológica localizada no município de Cuiabá. A equação para determinação do índice é:

$$
F M A=\sum_{n=1}^{n} \frac{100}{H}
$$

Onde: FMA é a Fórmula de Monte Alegre; $H$ é a umidade relativa do ar medida às 13:00h; e $n$ é o número de dias sem chuva.

Tabela 1. Restrições ao somatório da FMA, de acordo com a precipitação pluviométrica do dia.

\begin{tabular}{|c|c|}
\hline $\begin{array}{l}\text { Chuva do dia } \\
(\mathbf{m m})\end{array}$ & Modificação do cálculo \\
\hline$\leq 2,4$ & Nenhuma. \\
\hline 2,5 a 4,9 & $\begin{array}{l}\text { Abater } 30 \% \text { na FMA calculada na véspera e somar } \\
\qquad(100 / \mathrm{H}) \text { do dia. }\end{array}$ \\
\hline 5,0 a 9,9 & $\begin{array}{l}\text { Abater } 60 \% \text { na FMA calculada na véspera e somar } \\
\qquad(100 / \mathrm{H}) \text { do dia. }\end{array}$ \\
\hline 10,0 a 12,9 & $\begin{array}{l}\text { Abater } 80 \% \text { na FMA calculada na véspera e somar } \\
\qquad(100 / \mathrm{H}) \text { do dia. }\end{array}$ \\
\hline$>12,9$ & $\begin{array}{l}\text { Interromper a somatória }(\mathrm{FMA}=0) \text { e recomeçar o } \\
\text { cálculo no dia seguinte ou quando a chuva cessar. }\end{array}$ \\
\hline
\end{tabular}

A interpretação da classe de perigo de incêndio estimado pela FMA é feita por meio da escala apresentada na Tabela 2.
Tabela 2. Escala de perigo da Fórumula de Monte Alegre.

\begin{tabular}{cc}
\hline Valor da FMA & Classe de perigo \\
\hline$\leq 1,0$ & Nulo \\
1,1 a 3,0 & Pequeno \\
3,1 a 8,0 & Médio \\
8,1 a 20,0 & Alto \\
$>20,0$ & Muito alto \\
\hline
\end{tabular}

\section{Resultados}

Entre 2007 e 2015 foi registrada a ocorrência de incêndios no Parque Nacional da Chapada dos Guimarães (PNCG), onde os anos de 2007 e 2009 apresentaram os maiores números, com 19 e 10 ocorrências, respectivamente. Por meio de imagens do satélite AQUA foi detectado, no período compreendido entre 2007 e 2015, um total de 223 focos, seguido por imagens do satélite TERRA, com 238, e do NOAA com 179 focos de calor.

De acordo com a tabela 3, as imagens do satélite AQUA que apresentaram os maiores índices de focos de calor foram observadas nos anos em 2007 e 2012, ambos com 47 (21,08\%) focos detectados em 2010 com $74(33,18 \%)$ registros de focos. O satélite TERRA, detectou a maioria dos focos de calor em $2010(31,09 \%)$ e em $2015(25,63 \%)$, e o satélite NOAA, teve o maior registro de focos em 2010 (46,93\%) e em 2015 (31,84\%).

Tabela 3. Focos de calor (\%) observados pelos satélites de

2007 a 2015 no Parque Nacional da Chapada dos Guimarães, MT.

\begin{tabular}{cccccccccc} 
& \multicolumn{10}{c}{ ANOS } \\
\cline { 2 - 10 } Satélite & $\mathbf{2 0 0 7}$ & $\mathbf{2 0 0 8}$ & $\mathbf{2 0 0 9}$ & $\mathbf{2 0 1 0}$ & $\mathbf{2 0 1 1}$ & $\mathbf{2 0 1 2}$ & $\mathbf{2 0 1 3}$ & $\mathbf{2 0 1 4}$ & $\mathbf{2 0 1 5}$ \\
\hline NOAA & 8,38 & 1,12 & 0,56 & 46,93 & 0,56 & 7,82 & 2,79 & 0 & 31,84 \\
TERRA & 16,39 & 6,30 & 2,10 & 31,09 & 2,52 & 12,60 & 3,36 & 0 & 25,63 \\
AQUA & 21,08 & 2,69 & 3,14 & 33,18 & 0,90 & 21,08 & 4,48 & 0,45 & 13 \\
\hline
\end{tabular}

Em comparação ao número de ocorrência de incêndios observados, o satélite AQUA proporcionou

um registro da maior quantidade de focos de calor no parque em 2007, 2010, 2011, 2012, 2013 e 2015, superestimando assim a quantidade de focos de calor em relação ao número de ocorrências nos respectivos anos (Figura 2).

Em relação ao satélite TERRA, a superestimação dos focos em relação ao número de ocorrência dos incêndios foi detectada em todos os anos, excetuando-se 2009 e
2014, com os maiores valores observados em 2010, com 74 focos, e em 2007, com 39. Por meio de imagens do satélite NOAA registrou-se uma maior quantidade de focos em relação ao número de ocorrência em 2010, 2012, 2013 e 2015, com 2010 e 2015 apresentando os maiores números de registros, com 84 e 57 focos, respectivamente.

Em 2009 nenhum satélite registrou focos de calor 


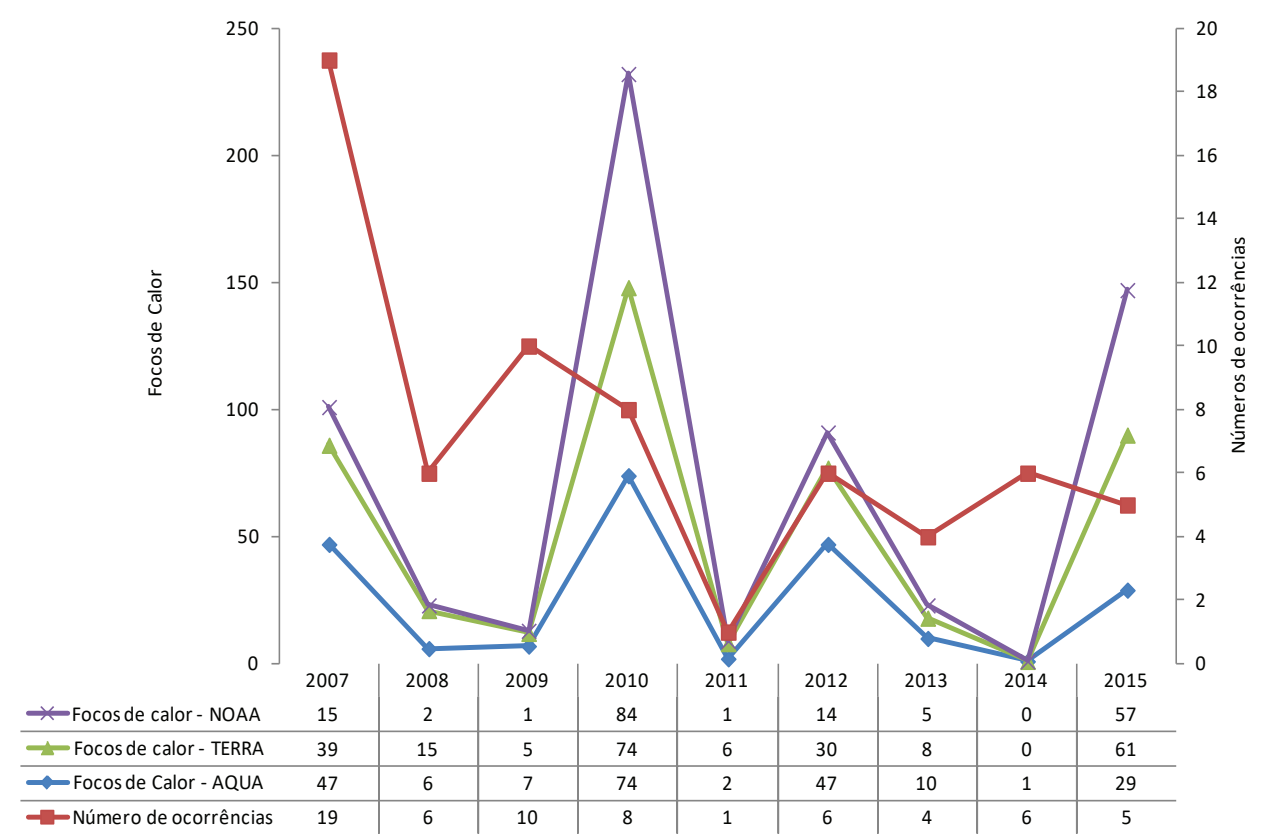

Figura 2. Número de focos de calor em relação às ocorrências de incêndios no Parque Nacional da Chapada dos Guimarães, de 2007 a 2015.

igual ou superior ao número de ocorrências de incêndios. Os satélites AQUA e TERRA forneceram dados sobre focos de calor que mais se aproximaram das ocorrências de incêndios registradas no PNCG.

Na distribuição dos focos de calor pelos meses no período de 2007 a 2015 , verificou-se que os maiores valores percentuais foram observados em agosto e setembro, para todos os satélites analisados. Por meio de imagens do satélite AQUA detectou-se um total de
$66(29,60 \%)$ focos de calor em agosto e $148(66,37 \%)$ em setembro.

Para imagens TERRA registrou-se 37 (15,55\%) focos de calor para o mês de agosto e $181(76,05 \%)$ para setembro e em imagens NOAA detectou-se 53 focos de calor em agosto e 125 em setembro, equivalendo a uma porcentagem de 29,61 e $69,83 \%$, respectivamente (Tabela 4).

Tabela 4. Focos de calor (\%) observados pelos satélites em relação aos meses do ano de 2007 a 2015 no Parque Nacional da Chapada dos Guimarães, MT.

\begin{tabular}{|c|c|c|c|c|c|c|c|c|c|c|c|c|}
\hline \multirow[b]{2}{*}{ Satélite } & \multicolumn{12}{|c|}{ MESES } \\
\hline & Jan & Fev & Mar & Abr & Mai & Jun & Jul & Ago & Set & Out & Nov & Dez \\
\hline NOOA & 0 & 0 & 0 & 0 & 0 & 0 & 0 & 29,61 & 69,83 & 0 & 0,56 & 0 \\
\hline TERRA & 0,42 & 1,12 & 0,42 & 1,12 & 0 & 0,42 & 0,42 & 15,55 & 76,05 & 4,62 & 0 & 0,42 \\
\hline AQUA & 0,45 & 0 & 0 & 0 & 0,45 & 1,35 & 1,35 & 29,60 & 66,37 & 0 & 0,45 & 0 \\
\hline
\end{tabular}

Em relação à distribuição das ocorrências de incêndios pelos meses no período de 2007 a 2015, o maior número de registros predominou em agosto e setembro, totalizando 15 e 30 ocorrências durante todo o período do estudo

(Figura 3).

Em todas as análises as ocorrências, tanto de incêndios como de focos de calor, apresentaram valores mais críticos correspondentes em agosto e setembro.

Também houve uma superestimação no número de focos de calor em relação às ocorrências de incêndios nos meses considerados críticos (agosto e setembro) em todas as imagens dos satélites analisados.
A análise da FMA foi realizada com os dados obtidos no período de 2007 à 2015, totalizando 3.287 dias, dos quais a maioria, pertencem à classe de perigo "muito alto", contemplando $25,82 \%$ das observações no período analisado (Tabela 5).

Tabela 5. Índice de perigo de incêndios no Parque Nacional de Chapada dos Guimarães pela Fórmula de Monte Alegre, no período de 2007 a 2015. 


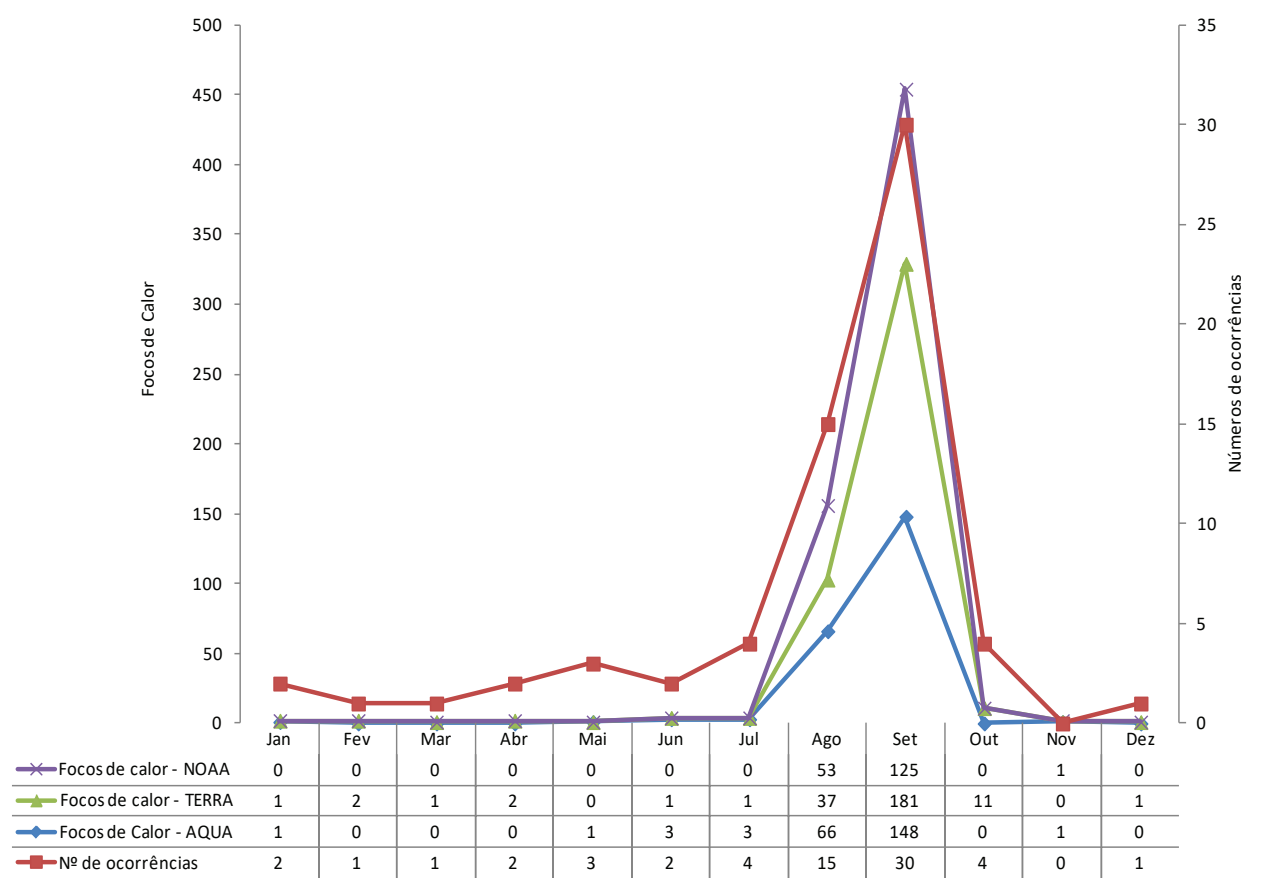

Figura 3. Número de focos de calor e de ocorrência de incêndios em relação aos meses do ano no Parque Nacional da Chapada dos Guimarães, de 2007 a 2015.

\begin{tabular}{cccccc}
\hline \multicolumn{5}{c}{ Classes de risco do índice de Monte Alegre } \\
\hline Ano & Nulo & Pequeno & Médio & Alto & Muito Alto \\
\hline 2007 & 40 & 76 & 66 & 52 & 131 \\
2008 & 137 & 73 & 77 & 44 & 35 \\
2009 & 116 & 52 & 76 & 84 & 37 \\
2010 & 33 & 70 & 77 & 48 & 137 \\
2011 & 37 & 73 & 70 & 63 & 122 \\
2012 & 36 & 83 & 85 & 61 & 101 \\
2013 & 40 & 72 & 93 & 87 & 73 \\
2014 & 46 & 81 & 100 & 66 & 72 \\
2015 & 36 & 49 & 68 & 71 & 141 \\
\hline Total & $\mathbf{5 2 1}$ & $\mathbf{6 2 9}$ & $\mathbf{7 1 2}$ & $\mathbf{5 7 6}$ & $\mathbf{8 4 9}$ \\
\hline$\%$ & 15,85 & 19,15 & 21,66 & 17,52 & 25,82 \\
\hline
\end{tabular}

Em todos os meses em que ocorreram incêndios (Tabela 6), considerando a média mensal, observou-se um total de 15 índices na classe "muito alto", oito índices na classe "alto", um "médio", três na classe "pequeno" e três na classe "nulo".

A comparação entre os registros de ocorrências de incêndios no PNCG, com o índice médio mensal no período de 2007 a 2015 , demonstrou que $87,69 \%$ desses registros ficaram dentro do esperado pela metodologia empregada (considerando classe de perigo alto e muito alto), sendo $60 \%$ pertencentes a classe de perigo "muito alto" e 27,69\% a classe de perigo "alto".

Em agosto e setembro, onde já foi constatado como o período com o maior número de registros de incêndios, observa-se também uma tendência no índice de perigo de incêndios em relação a esses registros. Nesses meses, nos anos de 2007 a 2015 houve um total de 10 índices "muito alto" e 4 "alto", propondo um bom desempenho entre os registros de incêndios e a indicação de grau de perigo fornecido pela FMA.

Tabela 6. Número de incêndios observados através dos registros de ocorrência de incêndios (ROI), em relação ao risco (RI) obtido por meio do cálculo da Fórmula de Monte Alegre. 


\begin{tabular}{|c|c|c|c|c|c|c|c|c|c|c|c|c|c|c|c|c|c|c|}
\hline \multirow[b]{2}{*}{ Mês } & \multicolumn{2}{|c|}{2007} & \multicolumn{2}{|c|}{2008} & \multicolumn{2}{|c|}{2009} & \multicolumn{2}{|c|}{2010} & \multicolumn{2}{|c|}{2011} & \multicolumn{2}{|c|}{2012} & \multicolumn{2}{|c|}{2013} & \multicolumn{2}{|c|}{2014} & \multicolumn{2}{|c|}{2015} \\
\hline & ROI & RI & ROI & RI & ROI & RI & ROI & RI & ROI & RI & ROI & RI & ROI & RI & ROI & RI & ROI & RI \\
\hline 1 & - & - & - & - & 1 & $\mathrm{~N}$ & - & - & 1 & $\mathrm{P}$ & - & - & - & - & - & - & - & - \\
\hline 2 & - & - & - & - & - & - & - & - & - & - & - & - & 1 & $\mathrm{P}$ & - & - & - & - \\
\hline 3 & - & - & - & - & 1 & $\mathrm{~N}$ & - & - & - & - & - & - & - & - & - & - & - & - \\
\hline 4 & - & - & - & - & 1 & $\mathrm{P}$ & - & - & - & - & - & - & 1 & M & - & - & - & - \\
\hline 5 & 2 & A & - & - & - & - & 1 & A & - & - & - & - & - & - & - & - & - & - \\
\hline 6 & 1 & MA & - & - & - & - & 1 & MA & - & - & - & - & - & - & - & - & - & - \\
\hline 7 & - & - & 1 & MA & 2 & A & - & - & - & - & 1 & MA & - & - & - & - & - & - \\
\hline 8 & 6 & MA & 2 & A & - & - & 2 & MA & - & - & 2 & MA & 1 & MA & 2 & MA & - & - \\
\hline 9 & 10 & MA & 1 & A & 5 & A & 2 & MA & - & - & 3 & MA & 1 & MA & 4 & A & 4 & MA \\
\hline 10 & - & - & 2 & $\mathrm{~N}$ & - & - & 2 & MA & - & - & - & - & - & - & - & - & - & - \\
\hline 11 & - & - & - & - & - & - & - & - & - & - & - & - & - & - & - & - & - & - \\
\hline 12 & - & - & - & - & - & - & - & - & - & - & - & - & - & - & - & - & 1 & A \\
\hline
\end{tabular}

\section{Discussão}

O número médio anual de ocorrências de incêndios no Parque Nacional da Chapada dos Guimarães (PNCG) $(7,22)$, foi inferior aos encontrados por Magalhães et al. (2011) no Parque Nacional da Serra da Canastra, onde os autores identificaram uma média de 10,43; Aximoff \& Rodrigues (2011) encontraram uma média de 29,63 incêndios por ano no Parque Nacional do Itatiaia; e Koproski et al. (2004), em estudo realizado no Parque Nacional de Ilha Grande, observaram a ocorrência anual média de 10,4 incêndios, no período de 1999 a 2003. Na Chapada dos Veadeiros, Fiedler et al. (2006) registraram média de cinco ocorrências, sendo menor que o valor encontrado no presente estudo.

Nos resultados encontrados no Paraná por Soares (1998), 43,1\% das ocorrências foram observadas em agosto e setembro e por Tetto et al. (2011), onde o período normal de ocorrência de incêndios se concentrou de junho a setembro, com 52,5\% dos registros.

Para Tetto et al. (2010a), é importante que as campanhas de sensibilização sejam iniciadas antes de julho e que a vigilância seja intensificada nos meses da estação normal de perigo de incêndios. $\mathrm{O}$ acompanhamento do perigo de incêndio em conjunto com o monitoramento de variáveis meteorológicas possui importância na caracterização de regiões que apresentam potencialidades de ocorrência de incêndios, possibilitando assim subsídios a atividades como: prevenção e combate aos incêndios, dimensionamento de infraestrutura e de equipes e vigilância e monitoramento dos incêndios (Deppe et al., 2004).

Em relação ao número de focos de calor, observou-se que em agosto, e setembro foram registrados os maiores índices de focos detectados nas imagens de todos os satélites analisados no presente estudo, corroborando com Machado et al (2014), que verificaram em Cuiabá os maiores valores de queimadas e focos de calor ocorrendo no final da estação seca (agosto-setembro). Ramos et al. (2011), analisando a temporada de incêndios florestais no Brasil em 2010, observaram que a maioria dos focos de calor também se concentrou em agosto e setembro, havendo também uma forte correlação entre a quantidade de chuvas e o número dos focos de calor, pois essas duas variáveis apresentaram uma correlação inversamente proporcional, ou seja, quanto maior a quantidade de chuvas, menor foi a quantidade de focos de calor.

Granemann \& Carneiro (2009) constataram, em estudo no Paraná, que no período das secas houve um maior número de focos registrados com imagens do satélite NOAA, com destaque para agosto e setembro, com $80,5 \%$ dos casos ocorridos em 2000, 64,3\% em 2001, 53,3\% em 2002, e 51,2\% em 2003. Em estudo realizado de 1998 a 2007, cerca de $98 \%$ das ocorrências de focos de calor registrados por satélites, na área do PNCG e entorno, ocorreram entre julho e outubro, com maior incidência foram setembro ( $45 \%$ do total de focos) e agosto (41\%) (ICMBio, 2009).

As observações demonstraram que houve um maior número de focos de calor em relação à quantidade de 
incêndios no PNCG, pois os satélites registrarem vários pixels durante um único incêndio, superestimando as informações, bem como alarmes falsos, ou seja, focos de calor que não se configuram como incêndios. Fiedler et al. (2006) observaram no Parque Nacional da Chapada dos Veadeiros, em Goiás, a ocorrência de 184 focos de calor no interior da unidade, através de imagens do satélite NOAA-12, no período de 1992 a 2003. Os autores também puderam constatar que existiu uma maior incidência de focos de calor em relação ao número de ocorrências de incêndios registradas no parque durante o período analisado.

Nos meses considerados críticos (maior ocorrência de incêndios) os satélites AQUA e NOAA não registraram em suas imagens focos de calor em outubro. Maio foi o único mês em que o satélite TERRA não registrou focos, de calor em relação às ocorrências de incêndios, demonstrando dessa forma uma maior sensibilidade às ocorrências de incêndios registradas no PNCG. Conforme mencionado por Tomzhinski et al. (2011), os satélites AQUA e TERRA carregam sensores MODIS e giram em órbita assíncrona e, juntos, os dois instrumentos conseguem adquirir imagens da Terra de 1 a 2 dias. Desta forma, o conjunto de informações dos sensores MODIS mostra-se a base de dados de focos de calor mais precisa e completa. Em relação a FMA, observou-se que o índice apresentou um bom desempenho para o PNCG, com a maioria dos incêndios ocorrendo nos dias em que a FMA indicou níveis críticos se concentrando na classe de perigo "muito alto".

Tetto et al. (2010a), obteve valores de 11,63\% (nulo), $15,25 \%$ (pequeno), 25,63\% (médio), 31\% (alto) e $15,24 \%$ pertenciam às classes de perigo de incêndio muito alto, demonstrando uma similaridade entre os resultados obtidos no presente trabalho. Souza et al. (2012) encontraram valores críticos (risco muito alto) em julho e agosto nas regiões Norte e Noroeste do Estado d Mato Grosso, demonstrando que esta metodologia pode ser recomendada para avaliação dos riscos de incêndios na região estudada, e que a FMA apresenta bom desempenho para as condições de Mato Grosso, o que corrobora com os dados obtidos nesse trabalho. Para Deppe et al. (2004), os índices de perigo possibilitam aos setores de prevenção e combate aos incêndios uma avaliação mais técnica do problema, considerando a possibilidade futura de ocorrência dos mesmos.

Torres \& Ribeiro (2008), afirmam que os índices de perigo de incêndios ajudam nas tomadas de decisões mais eficientes e adequadas de uma região, contribuindo para o no sistema de prevenção. De acordo com o INPE (2011), a identificação dos focos é auxiliada pelo sensoriamento remoto, uma vez que ao constatá-los nas imagens é possível antecipar decisões para impedir o alastramento do incêndio.

\section{Conclusões}

Em agosto e setembro foram registrados os maiores números de ocorrências de incêndios e as maiores quantidades de focos de calor, observando-se uma superestimação do número de focos em relação ao número incêndios, o que denota a necessidade de análises comparativas mais detalhadas sobre os meios de detecção dos satélites, em relação aos incêndios ocorridos no Parque Nacional da Chapada dos Guimarães (PNCG).

As imagens dos satélites AQUA e TERRA forneceram informações sobre focos de calor que mais se aproximaram das ocorrências de incêndios registrados no PNCG, onde o satélite TERRA detectou focos de calor na maioria dos meses, se diferenciando dos demais satélites.

Houve um bom desempenho da Fórmula de Monte Alegre em relação ao número de ocorrência dos incêndios, onde a maioria dos registros ficaram dentro da classe de risco alto e muito alto, demonstrando que a fórmula se apresentou eficiente em relação aos incêndios registrados, podendo a mesma ser adotada como ferramenta de prevenção dos sinistros no parque.

\section{Referências}

Aximoff, I. \& Rodrigues, R. de C. Histórico dos incêndios florestais no Parque Nacional do Itatiaia. Ciência Florestal, v. 21, n. 1, p. 8392, 2011. DOI: 10.5902/198050982750.

Batista, A. C. O uso dos retardantes no combate aéreo aos incêndios florestais. Floresta, v. 39, p. 5-10, 2009.

Cavalcanti, R. Capricho da natureza. UnB Revista, edição especial, p. $20-23,2000$.

Couto, J. et al. Plano de controle ambiental das obras de adequação do acesso ao Parque Nacional de Chapada dos Guimarães / MT. Chapada dos Guimarães, MT, 2006. Relatório não publicado.

Deppe, F. et al. Comparação de índice de risco de incêndio florestal com focos de calor no estado do Paraná. Floresta, v. 34, n. 2, p. 119-126, 2004. DOI: 10.5380/RF.V34I2.2382.

Fiedler, N. C. et al. Ocorrência de incêndios florestais no Parque Nacional da Chapada dos Veadeiros, Goiás. Ciência Florestal, v. 16, n. 2, p. 153-161, 2006. 
Global Wildland Fire Network: Regional South America Wildland Fire Management Network. Avaliable from: <https://www.fire.unifreiburg.de/GlobalNetworks/SouthAmerica/SouthAmerica.html>. 2007. Access on: 22 Set. 2017.

Graneman, N. D. C. \& Carneiro, G. L. Monitoramento de focos de incêndios e áreas queimadas com a utilização de imagens de sensoriamento remoto. Revista de Engenharia e Tecnologia, v. 1, n. 1, p. 61, 2009.

Ibama (Brasília, DF). Plano de ação emergencial do Parque Nacional da Chapada dos Guimarães. Brasília, DF, 1995. Documento não publicado.

ICMBio. Plano de manejo: Parque Nacional da Chapada dos Guimarães. Relatório final editado em abril de 2009. Disponível em $<$ http://www.icmbio.gov.br/portal/images/stories/imgs-unidadescoservacao/parna_chapada-dos-guimaraes.pdf $>$. Acesso em: 18 out. 2016.

ICMBio. Formação de brigadista de prevenção e combate aos incêndios florestais: apostila. Brasília, DF: Diretoria de Unidades de Conservação de Proteção Integral, Coordenação Geral de Proteção Ambiental, 2010. 87 p.

Instituto Nacional de Pesquisas Espaciais (Brasil). Inpe BDQueimadas: Banco de Dados de Queimadas. São José dos Campo, 2010. Disponível em: <http://www.dpi.inpe.br/proarco/ bdqueimadas/>. Acesso em: 23 mar. 2016.Koproski, L. de P. et al. Ocorrências de incêndios florestais no Parque Nacional de Ilha Grande - Brasil. Floresta, Curitiba v. 34, n. 2, p. 193-197, mai./ ago. 2004.

Machado, R. B. et al. Estimativas de perda da área do Cerrado brasileiro. Relatório técnico não publicado. Conservação Internacional, Brasília, DF. 2004.

Machado, N. G. et al. Efeito das condições meteorológicas sobre o risco de incêndio e o número de queimadas urbanas e focos de calor em Cuiabá-MT, Brasil. Ciência e Natura, v. 36, n. 3, p. 459-469, 2014. DOI: 10.5902/2179460X11892.

Magalhães, S. R. et al. Avaliação do combate aos incêndios florestais no Parque Nacional da Serra da Canastra. Floresta e Ambiente, v. 18, n. 1, p. 80-86, 2011.
Mato Grosso. Secretaria de Estado de Planejamento. Zoneamento socioecológico e econômico de Mato Grosso. 2007. Disponível em: $<$ www.seplan.mt.gov.br>. Acesso em: 07 jul. 2014.

Ramos, A. B. R. et al. Temporada de incêndios florestais no Brasil em 2010: análise de série histórica de 2005 a 2010 e as influências das chuvas e do desmatamento na quantidade dos focos de calor. In: SIMPÓSIO BRASILEIRO DE SENSORIAMENTO REMOTO, 15., 2011, Curitiba. Anais... São José dos Campos: INPE, 2011. p. 7902-7909.

Soares, R.V. Desempenho da "fórmula de monte alegre" índice brasileiro de perigo de incêndios florestais. Cerne, v. 4, n. 1, p. 87-99, 1998.

Soares, R. V. \& Batista, A.C. Incêndios florestais - Controle, efeitos e uso do fogo. Curitiba, 2007.

Souza, A. P. et al. Avaliação dos riscos de ocorrência de incêndios florestais nas regiões Norte e Noroeste da Amazônia Matogrossense. Scientia Plena, v. 8, n. 5, p. 1-14, 2012.

Tetto, A. F. et al. Comportamento e ajuste da Fórmula de Monte Alegre, na Floresta Nacional de Irati, Estado do Paraná. Scientia Forestalis, v. 38, p. 409-417, 2010a.

Tetto, A. F. et al. Subsídios à prevenção e combate a incêndios florestais com base no comportamento da precipitação pluviométrica na floresta nacional de Irati, Paraná. Ciência Florestal, v. 20, n. 1, p. 33-43, 2010 b.

Tetto, A. F. et al. Zoneamento do risco de incêndios florestais para o estado do Paraná, Brasil. In: SIMPÓSIO SULAMERICANO SOBRE PREVENÇÃO E COMBATE A INCÊNDIOS FLORESTAIS, 5., 2011, Campinas. Anais... Curitiba, 2011. CD-ROM.

Tomzhinski, G. W. et al. Avaliação da detecção de focos de calor por sensoriamento remoto para o Parque Nacional do Itatiaia. Biodiversidade Brasileira, v. 1, n. 2, p. 201-211, 2011.

Torres, F. T. P. \& Ribeiro, G. A. Índices de risco de incêndios florestais em Juiz de Fora/MG. Seropédica: Floresta e Ambiente, v. 15 n. 2 , p. 30-39, 2008. 
